\title{
Sharp wound debridement: patient selection and perspectives
}

This article was published in the following Dove Press journal: Chronic Wound Care Management and Research

\section{Connie Harris' \\ Patricia Coutts ${ }^{2}$ \\ Rose Raizman ${ }^{3,4}$ \\ Niki Grady ${ }^{5}$}

'Perfuse Medtec Inc., London, ON, Canada; ${ }^{2}$ Toronto Regional Wound Healing Clinic, Mississauga, ON, Canada; ${ }^{3}$ Professional Practice Scarborough and Rouge Hospital Centenary Site, Scarborough ON, Canada; ${ }^{4}$ Lawrence S. Bloomberg Faculty of Nursing, University of Toronto, Toronto, ON, Canada; ${ }^{5}$ Advanced Wound Healing Clinic, Windsor, ON, Canada

Correspondence: Connie Harris 14I Union Blvd. Kitchener, ON N2M 2S3, Canada

Tel +I 5197432046

Email connielynneharris@gmail.com

\begin{abstract}
Conservative sharp wound debridement, as part of the wound bed preparation paradigm, can be performed in a wide variety of settings including the patients' home or community clinic settings, by health care professionals who perform within their scope of practice and have been certified to be competent. This paper reviews the components that must be in place to ensure safe delivery of conservative sharp wound debridement for an increased number of clinicians, with organizational support, based on practices in a Canadian context. Expected goals are a cleaner wound bed, with an increased percentage of viable tissue, decreased amount of wound exudate, corresponding decreased risk of wound infection and malodor, and improved periwound skin.
\end{abstract}

Keywords: wound bed preparation, competency, non-viable tissue, scope of practice, CSWD

\section{Scope of the paper and background}

A person with a chronic wound presents many challenges to the health care provider (HCP). Understanding the cause of the wound, concerns of the patients, and the management of the local wound care is essential for the HCP.

Debridement is an important element for the Wound Bed Preparation paradigm to promote healing ${ }^{1}$ under the heading "local wound care." It is interesting to note that reference to debridement goes back to the 18th century when French physicians would make an incision to relieve the pressure caused by the swelling associated with wounds from war injuries. During the First World War, the term "debridement" was redefined to include excision of all non-viable and foreign materials. ${ }^{2}$ The choice for the method of debridement - autolytic, biological, enzymatic, mechanical, or sharp - in part depends on the status of the wound, the patient preference, and the work environment as well as the knowledge, skill, and judgment of the HCP. This article discusses patient selection and perspectives for conservative sharp wound debridement (CSWD), from the perspective of nurses. Despite such a long history, limited literature is available on the topic of sharp wound debridement, and even less for the conservative method practiced by nurses. The authors conducted a literature review in PubMed and Cinahl for papers from 1995 to 2013. The words "wound debridement" resulted in 14,239 articles, "sharp debridement" 219, "sharp wound debridement" 181, and "conservative sharp debridement" 21 articles. Only six of these were relevant. Due to this scarcity, and also due to the authors' experience, involvement in dissemination and education, and familiarity with Canadian literature on CSWD, we chose to include it in this paper. 
CSWD is defined by the Canadian Association for Enterostomal Therapy (now Nurses Specialized in Wound, Ostomy and Continence Canada [NSWOCC]) as the removal of loose, devascularized tissue, callous or hyperkeratotic tissue with the aid of a scalpel, scissors, or curette above the level of viable tissue. ${ }^{3}$ This skill requires clear direction within organizations as to who can perform therapeutically, ethically, safely, and within the scope of practice for their health profession, as determined by law. ${ }^{4}$ Alexander Pope coined the phrase "fools rush in where angels fear to tread" in his Essay on Criticism in $1711 .^{5}$ This wisdom can be applied to health care professionals who perform CSWD without evaluating the patients' suitability and/or without having the knowledge, skill, judgment, and authority to do so. However, recognizing when debridement is needed, knowing when it is safe to do, and deciding which method is appropriate to the patient situation are crucial.

\section{Benefits and indications}

Necrotic tissue and slough are key contributors to wound chronicity and thus debridement is necessary for wound healing. ${ }^{6,7}$ CSWD is an appropriate method of debridement when there is devitalized (necrotic) tissue such as slough or eschar, peri-wound callus or hyperkeratosis that can be clearly separated from viable tissue, where other types of debridement will not work, and/or where speed is of the essence. It can be used in conjunction with other methods of debridement. For example, autolytic debridement using a moisture-retentive dressing or enzymatic debridement with collagenase can be used prior to performing CSWD to soften and degrade the devitalized tissue and can be continued after CSWD if the wound bed is not $100 \%$ debrided. Mechanical debridement can also complement CSWD by removing slough and debris that cannot be picked up with a tissue forceps. Acceptable methods of mechanical debridement include wound irrigation using a single-use, 7-12 psi pre-filled bottle or a $30-35 \mathrm{~mL}$ syringe and an 18- or 19-gauge intravenous catheter/wound irrigation tip with $100-150 \mathrm{~mL}$ solution. ${ }^{8}$ Another option is a sterile single-use pad made up of monofilament polyester fibers cut at angled tips to penetrate irregularly shaped areas. This removes devitalized tissue and wound debris, reducing pain and anxiety related to other methods of debridement. ${ }^{9,10}$ Patients can be taught self-care with any of these methods to help debride their wound.

Surgical debridement (into viable tissue) is effective in stimulating healing, for example, with recalcitrant chronic venous ulcers ${ }^{11,12}$ and can be complemented by CSWD between episodes. In plantar surface diabetic foot ulcers (DFUs), where peri-wound callus or hyperkeratotic tissue pre- vents wound contraction and re-epithelialization, CSWD can reduce pressure by up to $30 \%$, improving the chance of healing but may require serial debridement episodes. ${ }^{13-17}$ CSWD cannot saucerize the wound, removing skin undermining which requires surgical debridement, ${ }^{18}$ and it is important that the clinician knows the difference, and when each is indicated. Debridement is important for creating an optimal healing environment for all types of wounds as necrotic tissue prevents timely progressions of wounds from the inflammatory to proliferative stage. CSWD leads to the release of cytokines and mediators of inflammation. ${ }^{6,19}$ Determining whether to use CSWD or to implement other methods of debridement involves expert knowledge and critical thinking skills.

\section{Goals of treatment}

CSWD is safe, well tolerated, and can be performed in an outpatient setting. ${ }^{14}$ Performing CSWD to remove non-viable tissue should achieve a cleaner wound bed, with an increase in the percentage of viable tissue, decreased amount of wound exudate, with a corresponding decreased risk of wound infection and malodor. If the wound has been stalled in a chronic inflammatory state due to necrotic tissue/debris, it moves into an acute proliferative phase and starts to form granulation tissue. When used in a palliative situation, where wound healing is not possible, it may decrease odour, pain and/or the risk of bleeding by debulking the weight of the non-viable tissue. Both malodor and pain affect the patients' perceived quality of life. When reducing peri-wound callus, the peri-wound skin should be more pliable and have the appearance of healthy skin.

\section{Patient selection}

A number of components of assessment are necessary to determine whether CSWD is appropriate for the patients. ${ }^{3,20}$

1. Assess the wound using a validated wound assessment tool such as the Bates-Jensen Wound Assessment tool ${ }^{21,22}$ and document the need and readiness of the wound to receive CSWD.

2. Determine the wound etiology and analyze whether CSWD is safe to perform. If it is a malignant wound, or pyoderma gangrenosum or vasculitis are present, a primary care specialist consult should be made rather than proceeding. ${ }^{3}$ If the wound is in a previously radiated area of skin, the tissue can be very fibrotic and friable and should also be referred to primary care. ${ }^{3}$

3. Assess the status of the patients' comorbid conditions such as poor glycemic control, renal disease, malnutrition, auto-immune disorders, heart disease or peripheral 
vascular disease, cancer, advanced age, dementia, and immunosuppression. ${ }^{3}$ Presence of a clotting disorder may require a specialist consult before proceeding. "Healability" is impacted by whether the arterial blood supply is adequate for healing. ${ }^{3,20}$ If the supply is inadequate, or there is intact dry gangrene, CSWD is generally considered to be inappropriate. The exception to this may be when a previously dry area of eschar starts to separate from the surrounding viable tissue, and produces exudate, or appears infected. At that point, the risk of leaving the necrotic tissue in place is greater than that of removing it. ${ }^{3}$ The patients' lifestyle choices such as smoking, alcoholism, or unwillingness to follow recommendations to heal the wound such as pressure offloading may make healing impossible.

4. While the comorbidities may impact the patients' ability to heal, medications such as anticoagulants can affect bleeding time and thus the patients need to bring their full medication list for the nurse to examine. It is also important to consider laboratory test values such as International Rationalized Ratio, platelet count, and so on prior to undertaking CSWD in the event of inadvertent injury and bleeding.

5. Evaluate the presence of pain and whether it is incidental, procedural, or neuropathic in origin. Although CSWD should not cause pain in and of itself, the process of lifting non-viable tissue to remove it can cause pain to the underlying viable tissue, and adequate pain relief must be planned and in place. Pre-planning for oral analgesia to be taken or topical anesthesia such as topical lidocaine prilocaine cream to be applied prior to the procedure is important and will contribute to a more successful CSWD intervention. ${ }^{3,23,24}$
6. If the wound is infected with a new or spreading infection, assessment by a primary care provider is needed as soon as possible. It may not be suitable to alter the wound by performing CSWD prior to the examination. ${ }^{3}$

7. The anatomical location of the wound must be considered. ${ }^{3}$ CSWD should not be performed when the wound is in proximity to blood vessels, grafts, prosthesis, tendons or a dialysis fistula, or on the patients' hands or face. ${ }^{3}$ If the practitioner cannot fully visualize the wound bed, do not proceed.

8. The physical setting may not be conducive to safe performance where there is inadequate lighting or supplies. If the wound cannot be clearly visualized due to poor lighting, or sterile supplies are not available, it should not be performed. An involuntary motion by the patient, whether in response to painful stimuli or spasticity because of a neuromuscular condition, may jeopardize the safety of the procedure. ${ }^{3}$ If there is not a second person to stabilize the involuntary movement in a limb of a person with spasticity, CSWD should not be performed at that time.

9. When unsure and/or where orders must be received to perform CSWD, consult with the primary HCP. A checklist of situations of when not to perform CSWD is found in Box 1.

10. Informed consent must be obtained from the patient, having explained both the benefits and risks of performing and not performing the procedure. The European Wound Management Association (EWMA) Debridement Document Appendix 3 recommends that this be a written consent ${ }^{19}$ and provides a sample clinician safety checklist.

\section{Box I When not to perform CSWD:3,19,25-27}

- The practitioners are not competent and certified by their organization to perform CSWD.

- CSWD is outside the practitioners' scope of practice.

- Patient/Power of Attorney does not provide written consent.

- The anatomy of the wound and surrounding tissue is unclear and may be near blood vessels, other structures, etc.

- The wound is friable (bleeding is occurring).

- There is ineffective pain management.

- Antibiotic therapy has not resolved the infection or infection is new and spreading.

- This is a non-healing ulcer due to poor vascularization.

- The patient is medically unfit.

- Sterile sharp instruments are not available.

- Lighting is inadequate for safe visualization.

- There is a risk of involuntary movement and no second person to help to immobilize the patient.

- There is densely adherent necrotic tissue and the interface between viable and non-viable tissue cannot be clearly identified.

- Patient has impaired blood clotting condition or taking anticoagulant medicines, increased risk of bleeding or exposure of blood vessels such as in malignant wounds.

Abbreviation: CSWD, conservative sharp wound debridement. 


\section{Regulatory and sector considerations}

Performing CSWD may be independently restricted either by safety factors regarding the physical setting or by the legislation that governs a health care sector. Provinces and territories within Canada have regulatory bodies that have implemented regulations defining the scope of practice of nurses regarding CSWD. In the Province of Ontario, Canada (where all the authors reside and work), under the Nursing Act $1991^{28}$ Registered nurses (RNs) may initiate and/or provide an order for an $\mathrm{RN}$ or registered practical nurse (RPN) to perform debridement if they meet certain requirements stipulated by their regulatory college. ${ }^{29}$ However, they must follow their agency's policies and procedures regarding this, under which they may be required to have an order from the primary care provider to do so. The sector in which the patient is receiving care can also influence the ability to perform CSWD. In Ontario, both the Public Hospital and Long-Term Care Acts preclude the ability of an RN to initiate CSWD (without an order from primary care). There is no legislation limiting initiation in the community sector. It is imperative that any HCP wishing to perform CSWD needs to have a full and complete understanding of the standards of practice of their regulatory body, as well as any limitations imposed by Health Acts or legislation, and their agency policy.

\section{Competency}

In general, a competent health care professional who has participated in extensive training through theory and mentorship has the knowledge, skill, and judgment to perform CSWD and practices within the scope of practice stated by provincial policies and institutional policies. Nurses performing CSWD must be competent in their knowledge of current organizational infection practices and other hands-on competencies such as ability to control bleeding, pain, distinguish between viable and non-viable tissue, and ability to effectively utilize secondary debridement techniques. ${ }^{3,19,20,30}$ However, there is a great variation in preparation and mentoring. ${ }^{31}$ In 2013, RoddNielsen and Harris ${ }^{4}$ published the responses of 397 nurses performing CSWD in all types of care settings in Canada from outpost nursing stations to hospital wards, homes, and long-term care facilities. The most frequently reported formal wound care education was a 2 -day course $(59 \%$; $n=220)$, followed by an Enterostomal Therapist (NSWOCC) Course (42; $\mathrm{n}=155$ ) and the International Interdisciplinary Wound Care Course $(26 \% ; n=98)$, with overlapping preparation being evident. However, none of these courses certify participants competent to perform CSWD, so the responsibility for com- petency falls on the individual and the organization for whom they work. Eleven percent of respondents $(n=47)$ reported having taken no formal wound course and $7 \%(n=27)$ taught themselves to perform CSWD.

While nurses recognized as wound experts (Enterostomal Therapists [NSWOCC] in Canada, tissue viability nurses in the United Kingdom, and Wound, Ostomy, Continence Nurses in the United States) $)^{3,430,31}$ most frequently perform CSWD, there is a growing and important role for frontline nurses to be competent. In an educational and quality improvement initiative to train both RNs and RPNs to perform CSWD for patients with DFUs, increased levels of satisfaction of the patients and the nurses were seen. ${ }^{32,33}$ This has subsequently proven to be a sustainable skill. After 3 years, it was recognized that patients receiving CSWD with Total Contact Casting in one of these settings were healing faster than similar patients where CSWD was not being performed. ${ }^{34}$

CSWD is a specialized level of wound care that requires practice-based, mentored educational preparation and a regulatory process for ongoing competency assessment, and should be clearly outlined in organizational policies. ${ }^{30}$ In the authors' opinion, nurses practicing CSWD could benefit from development and dissemination of a set of national standards and competencies for this high-risk wound intervention.

\section{Risk and complications}

Complications can arise unexpectedly while performing medical procedures. Although involving removal of non-viable tissue, CSWD is an invasive procedure where there needs to be an integral understanding of comorbidities, medications, anatomical structures, tissue types, and patient stability. In Canada, unintentional bleeding was reported as the most common complication self-reported by $98 \%$ of the respondents who answered this question, ${ }^{4}$ while infection $(4 \% ; n=8)$ and profuse bleeding $(3 \% ; n=6)$ occurred much less frequently. In contrast, the EWMA document ${ }^{19}$ identified the spread of infection, caused by a breach in sterility, an unprepared site, or use of an improper drape or non-sterile instruments as a frequent complication, and included both sharp and surgical debridement in this observation. Clinicians performing CSWD must also recognize the risks of their own or patient fatigue, or patient discomfort, and should limit a CSWD session to what they can comfortably accommodate. The load of necrotic tissue does not need to be removed in one setting, and in fact, serial debridement of necrotic tissue is recommended. This is described as removing thin layers or small amounts during sequential sessions until all of the non-viable tissue is removed. ${ }^{3}$ 


\section{Liabilities and limitations}

A system to assess clinician competency is critical in safeguarding the patient and practitioner from harm and to protect the practitioner and employer from liability. ${ }^{30-33}$ Those performing CSWD need to ensure that they are covered by organizational insurance for liability or may want to secure their own insurance to protect themselves in the event of an adverse event. ${ }^{32,33}$

Patients experience ongoing psychological stress due to the focus on the wound appearance and odor, and the delay in restoring skin functionality. ${ }^{11,35}$ There is also risk to the patient if CSWD is needed but not performed, or arrangements are not made for primary care to perform surgical debridement or CSWD. Necrotic tissue and debris increase the risk of bacterial growth and abscess or infection formation, cause chronic inflammation, and add to the metabolic load. There may be a link between biofilms and slough, thought to be a by-product of biofilm. ${ }^{36}$ Slough is considered to be a waste product of the host-immune response to effectively clear cellular debris and is composed of microorganisms, fibrin, albumin and immunoglobulin, collagen, and white blood cells. It theoretically provides an ideal support for the attachment and proliferation of microbes, supporting subsequent polymicrobial biofilm formation. ${ }^{36} \mathrm{CSWD}$ does not remove viable tissue, so cannot improve the vascularity of wound bed or aid in the removal of biofilm originating in viable tissue. ${ }^{3,26,27}$ Sharp debridement converts a chronic wound into an acute wound by removing viable yet chronically inflamed and senescent tissue, helping the progression through the inflammatory to the proliferatory stage. ${ }^{19}$

\section{Documentation}

Documentation regarding CSWD should include the patient's informed consent ${ }^{19}$ and wound assessment using a validated tool ${ }^{20}$ such as the BWAT ${ }^{21,22}$ to quantify and describe what the status of the wound is and to demonstrate why CSWD is needed. While CSWD can be documented narratively, the Debridement Performance Index ${ }^{18}$ lends itself to CSWD regardless of the etiology. It was developed to assess whether the debridement for DFUs had been performed adequately and how it is correlated to healing. There are three categories: debridement of 1) callus, 2) undermining ulcer edge, and 3 ) wound bed necrotic tissue. A maximum score of 2 can be assigned to each category using the following criteria: $0=$ debridement needed but not performed, $1=$ debridement needed and performed, and $2=$ debridement not needed. The total score ranges from 0 to 6 , with the highest number being the optimal score. Whichever method is chosen, the need to document thoroughly cannot be stressed enough, including whether there were any unexpected events such as bleeding, what was done, and what teaching the patient has received.

\section{Cost-effectiveness}

Unfortunately, there is very little literature about the costbenefits of performing CSWD. A 2007 Canadian comparative study evaluated the cost-benefit of sharp debridement in community foot-ulcer care to attain a clean wound bed. ${ }^{37}$ Wound specialists, including ET (NSWOCC) nurses, using (conservative) sharp wound debridement took $2-5$ visits to achieve a clean wound bed, versus 29 visits for community nurses using mechanical forced irrigation. The average cost per ulcer to achieve a clean wound bed was calculated to be $\$ 304.00$ (CDN) to $\$ 445.00$ for the wound specialists and $\$ 1,820$ for community nurses, a difference of $\$ 1,375.00$ $\$ 1,516.00$. CSWD can be performed by a single practitioner, and ideally at the time when it is needed, without a wait. Necessary materials include sterile, usually single-use disposable scalpel or iris scissors, tissue forceps, and possibly a curette. Other sterile materials can include gauzes, gloves, sterile solutions, and dressings and containers for swabs for culture and sensitivity if indicated. In some settings or situations, sterile drapes and antiseptic solutions are required. ${ }^{19}$

\section{Case study}

Written informed consent was obtained from the patient for the publication of all case details and images. He is a 67-year-old semi-retired gentleman, who works part time at a large home improvement store. His hobbies are traveling and gardening. He has a history of Type 1 diabetes, hypertension, hypercholesterolemia, and a heart valve replacement. He has had recurrent ulcerations on his right foot which were associated with callus over the bony prominence on his third/fourth metatarsal heads. This area required regular sharp conservative debridement by both his nurses and a chiropodist, along with proper pressure redistribution. $\mathrm{He}$ did have appropriate custom orthotics and shoes. He did attempt to wear a removable cast walker but found that it bothered his hip and back. Even with regular sharp conservative debridement and appropriate footwear, his wounds would heal, then with an increased activity he would develop hemorrhagic bullae leading to another ulceration (Figure 1). These required deroofing of the bullae to reveal the underlying ulcer (Figures 2 and 3). Because of the repetition of these occurrences, he consulted with a foot and ankle surgeon who shaved down the two problematic prominent bones in his foot. He is currently ulcer free and carries on with CSWD of 


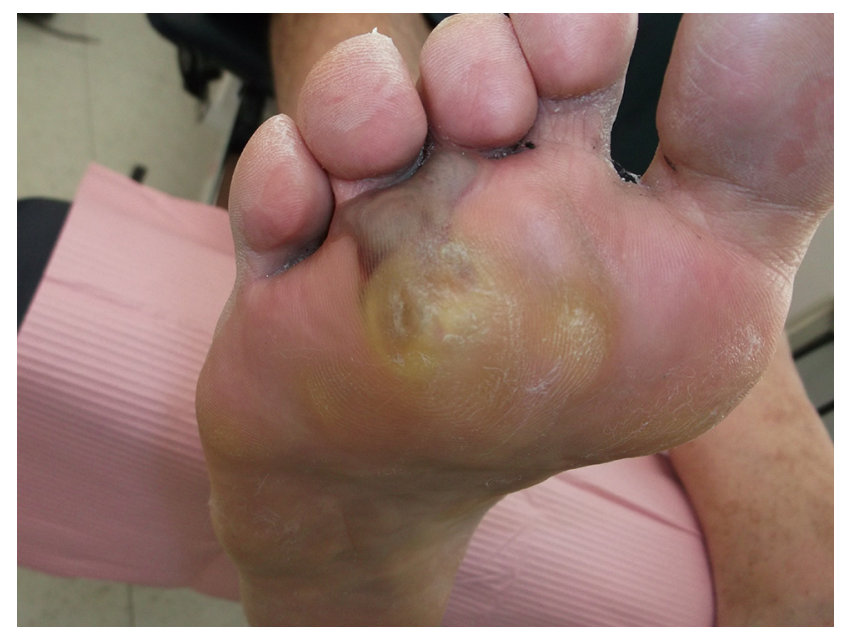

Figure I Hemorrhagic bullae leading to another ulceration.

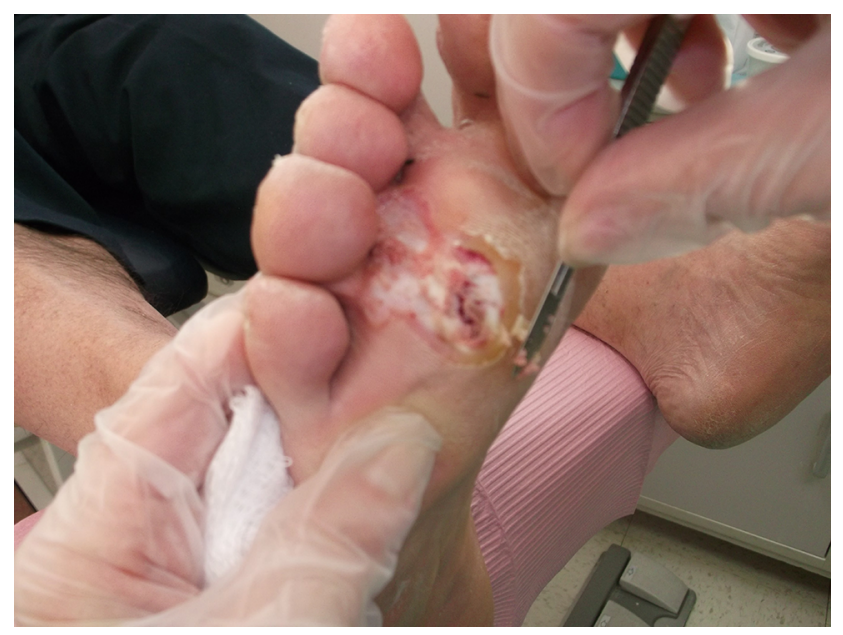

Figure 2 Deroofing of the bullae to reveal the underlying ulcer.

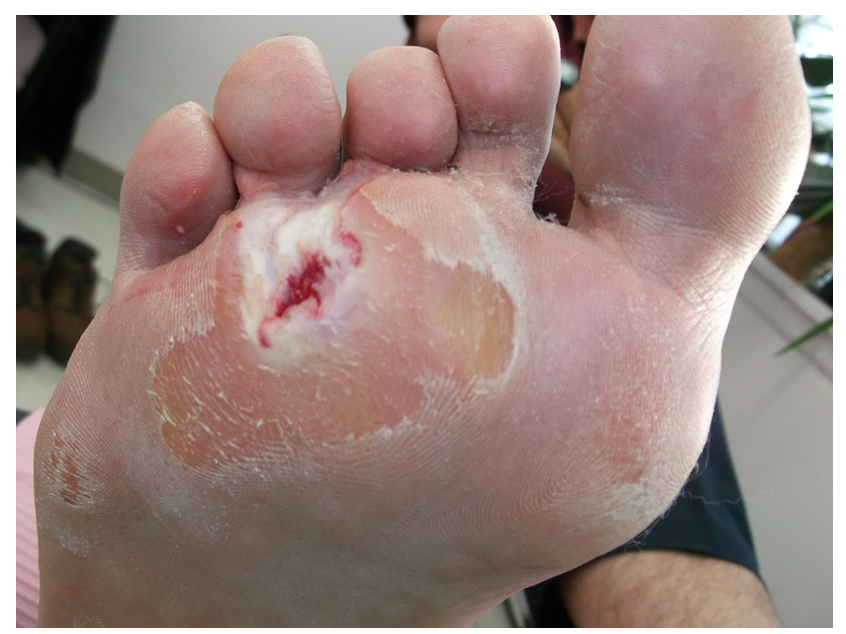

Figure 3 Deroofing of the bullae to reveal the underlying ulcer.

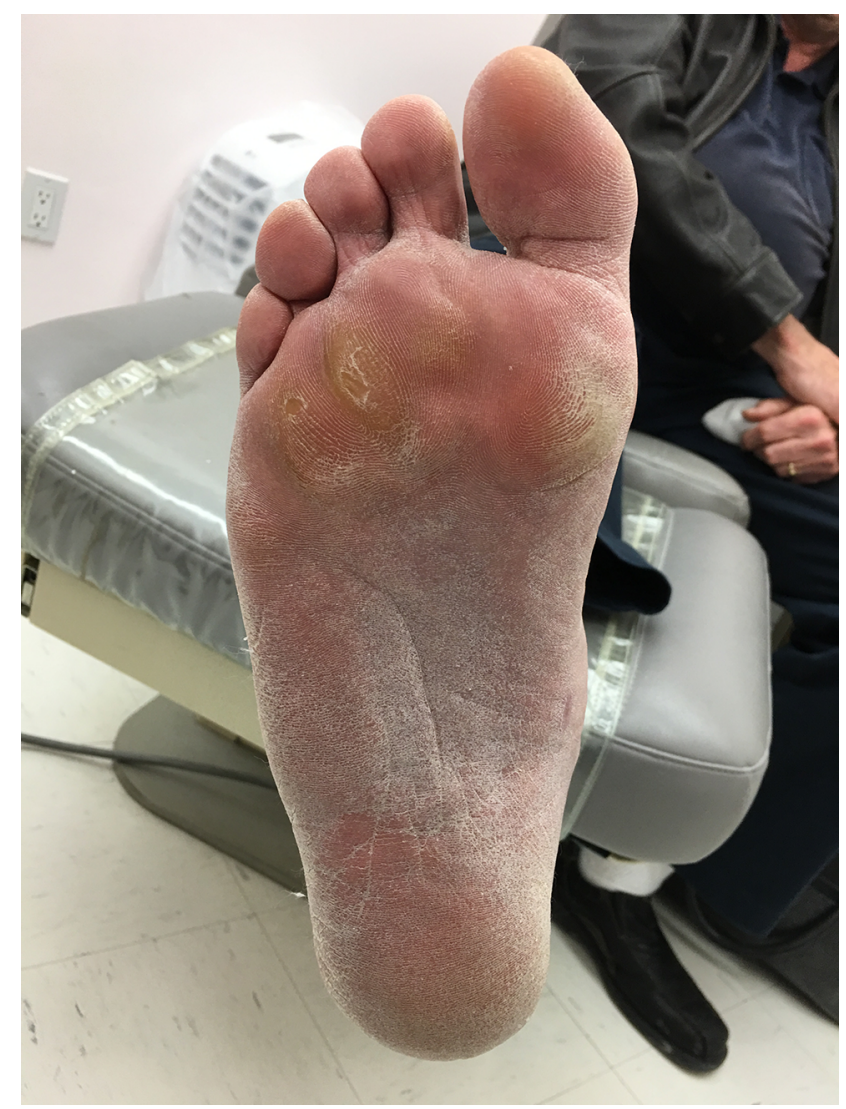

Figure 4 Ongoing maintenance debridement.

the callus on a regular basis (Figure 4). He wears his custom orthotics and shoes always as he continues to travel, garden, and work part-time.

\section{Conclusion}

Debridement unequivocally is the tenet of wound bed preparation. ${ }^{1}$ Sharp debridement can only be performed by HCPs within their scope of practice, who are competent in dealing with complications such as post-debridement hemorrhage, ${ }^{26}$ and in settings with appropriate equipment like hyfrecators and local or general anesthesia. In contrast, CSWD can be performed in a wide variety of settings including the patients' home or community clinic settings. There is an increasing need, given the body of knowledge illustrating the efficacy and efficiency of this method, for an increased number of clinicians to perform CSWD, if they possess the proper knowledge, skills, and judgment in performing the CSWD, controlling the pain and engaging the patient. Agencies and governing bodies must support clinicians with proper policies based on regulations and law and ensure that a mechanism for efficient mentoring exists to sustain individual and institutional competencies. 


\section{Disclosure}

The authors report no conflicts of interest in this work.

\section{References}

1. Sibbald RG, Williamson D, Orsted HL, et al. Preparing the wound bed - debridement, bacterial balance, and moisture balance. Ostomy Wound Manage. 2000;46(11):14-22, 24-28, 30-35; quiz 36-37.

2. Guthrie HC, Clasper JC. Historical origins and current concepts of wound debridement. J R Army Med Corps. 2011;157(2):130-132.

3. Rodd-Nielsen E, Brown J, Brook J. CAET evidence-based recommendations for conservative sharp wound debridement; 2011. Available from: http://www.caet.ca/caet-english/documents/ caet-conservative-sharpwound-debridement-bpr.pdf. Accessed January 2, 2018.

4. Rodd-Nielsen E, Harris CL. Conservative sharp wound debridement: an overview of Canadian education, practice, risk, and policy. $J$ Wound Ostomy Continence Nurs. 2013;40(6):594-601.

5. Pope A. An Essay on Criticism. 1. London: Printed for W. Lewis in Russel Street, Covent Garden; and Sold by W. Taylor at the Ship in Pater-Noster Row, T. Osborn near the Walks, and J. Graves in St. James Street. 1711; 2017. Available from: http://www.public-library. uk/ebooks/33/23.pdf. Accessed January 25, 2018.

6. Milne J. Wound-bed preparation: the importance of rapid and effective desloughing to promote healing. Br J Nurs. 2015;24(Suppl 20):S52-S58.

7. Percival SL, Suleman L. Slough and biofilm: removal of barriers to wound healing by desloughing. $J$ Wound Care. 2015;24(11):498-510.

8. Harris CL, Holloway S. Development of an evidence-based protocol for care of pilonidal sinus wounds healing by secondary intent using a modified Reactive Delphi procedure. Part 2: methodology, analysis and results. Int Wound J. 2012;9(2):173-188.

9. National Institute for Health and Care Excellence. NICE Medical Technology Guidance SCOPE: Debrisoft for the debridement of acute and chronic wounds. 1.1. Available from: https://www.dovepress.com/ author_guidelines.php?content_id=2967. Accessed January 16, 2018.

10. Paustian C, Stegman MR. Preparing the wound for healing: the effect of activated polyacrylate dressing on debridement. Ostomy Wound Manage. 2003;49(9):34-42.

11. Gethin G, Cowman S, Kolbach DN. Debridement for venous leg ulcers. Cochrane Database Syst Rev. 2015 (9):CD008599.

12. Williams D1, Enoch S, Miller D, Harris K, Price P, Harding KG. Effect of sharp debridement using curette on recalcitrant nonhealing venous leg ulcers: a concurrently controlled, prospective cohort study. Wound Repair Regen. 2005;13(2):131-137.

13. Young MJ, Cavanagh PR, Thomas G, et al. The effect of callus removal on dynamic plantar foot pressures in diabetic patients. Diabet Med. 1992;9(1):55-57.

14. Steed DL, Donohoe D, Webster MW, Lindsley L. Effect of extensive debridement and treatment on the healing of diabetic foot ulcers. Diabetic Ulcer Study Group. J Am Coll Surg. 1996;183(1):61-64.

15. Potter J, Potter MJ. Effect of callus removal on peak plantar pressures. Foot. 2000;10(1):23-26.

16. Slater RA, Hershkowitz I, Ramot Y, Buchs A, Rapoport MJ. Reduction of digital plantar pressure by debridement and silicone orthosis. Diabetes Res Clin Pract. 2006;74(3):263-266.

17. Botros M, Kuhnke J, Embil J. Best practice recommendations for the prevention and management of diabetic foot ulcers. Wounds Canada; 2017. Available from: www.woundscanada.ca/docman/public/health-careprofessional/bpr-workshop/895-wc-bpr-prevention-and-management-ofdiabetic-foot-ulcers-1573r1e-final/file. Accessed January 29, 2018.

18. Saap LJ, Falanga V. Debridement performance index and its correlation with complete closure of diabetic foot ulcers. Wound Repair Regen. 2002;10(6):354-359.
19. Strohal R, Apelqvist J, Dissemond J, et al. EWMA document: debridement. $J$ Wound Care. 2013;22(Suppl 1):S1-S52.

20. Orsted HL, Keast DH, Forest-Lalande L, Kuhnke JL, O'Sullivan-Drombolis $\mathrm{D}$, Jin $\mathrm{S}$, et al. Best practice recommendations for the prevention and management of wounds. In: Foundations of Best Practice for Skin and Wound Management. A supplement of Wound Care Canada; 2017. Available from: www.woundscanada.ca/docman/public/health-careprofessional/165-wc-bpr-prevention-and-management-of-wounds/file. Accessed January 25, 2018.

21. Bates-Jensen BM, Mcnees P. Toward an intelligent wound assessment system. Ostomy Wound Manage. 1995;41(7A Supp1):80S-86S; discussion $87 \mathrm{~S}$.

22. Harris C, Bates-Jensen B, Parslow N, Raizman R, Singh M. The BatesJensen Wound Assessment Tool (BWAT): development of a pictorial training guide for nurses. Wound Care Canada. 2009;7(9):33-38.

23. Vanscheidt W, Sadjadi Z, Lillieborg S. EMLA anaesthetic cream for sharp leg ulcer debridement: a review of the clinical evidence for analgesic efficacy and tolerability. Eur J Dermatol. 2001;11(2): 90-96.

24. Holm J, Andrén B, Grafford K. Pain control in the surgical debridement of leg ulcers by the use of a topical lidocaine-prilocaine cream, EMLA. Acta Derm Venereol. 1990;70(2):132-136.

25. Leak K. How to... Ten top tips for debridement. Wounds Int. 2012;3(1):21-23.

26. Wound Healing and Management Node Group. Surgical and conservative sharp wound debridement for chronic wounds. Wound Pract Res. 2011;19(1):29-31.

27. Education and Professional Development Subcommittee (EPDSC). AWMA module accreditation. Module Seven: Conservative Sharp Wound Debridement; 2015. Available from: http://www.woundsaustralia.com.au/publications/module_7_awma_cswd-jul13.pdf.pdf. Accessed January 20, 2018.

28. Nursing Act Province of Ontario. Canada. 1991, S.O. 1991, c. 32. Available from: https://www.ontario.ca/laws/statute/91n32. Accessed January 1, 2018.

29. Legislation and Regulation RHPA: Scope of Practice, Controlled Acts Model. College of Nurses of Ontario; 2017. Available from: http:// www.cno.org/globalassets/docs/policy/41052_rhpascope.pdf. Accessed January 1, 2018.

30. Harris R. The nursing practice of conservative sharp wound debridement: promotion, education \& proficiency. Wound Care Canada. 2009;7(1):22-30.

31. Fairbairn K, Grier J, Hunter C, Preece J. A sharp debridement procedure devised by specialist nurses. J Wound Care. 2002;11(10):371-375.

32. Harris C, Burns-Gibson S, Harris A, Browne C, Byrnes B. Conservative sharp wound debridement by community nurses for clients with diabetic foot ulcers: a quality improvement initiative. Diabetic Foot Canada. 2014;2(1):31-37.

33. Harris C. Creating a Conservative Sharp Wound Debridement (CSWD) Education Program for Frontline Nurses. Wound Care Canada. 2013;11(2):18-24.

34. Walker C. Verbal update re: Sustainability of CSWD program. 2017.

35. Baharestani M. The clinical relevance of debridement. In: Baharestani $\mathrm{M}$, et al. The Clinical Relevance of Debridement. Berlin: SpringerVerlag; 1999.

36. Percival SL, Suleman L. Slough and biofilm: removal of barriers to wound healing by desloughing. J Wound Care. 2015;24(11): 498-510.

37. Shannon R, Harris C, Harley C, et al. The importance of sharp debridement in foot ulcer care in the community: a cost-benefit evaluation. Wound Care Canada. 2007;5(Suppl 1):S51-S52. 


\section{Publish your work in this journal}

Chronic Wound Care Management and Research is an international, peer reviewed, open access, online journal publishing original research, reviews, editorials, and commentaries on the causes and management of chronic wounds and the major issues related to chronic wound management. Topics also include chronic wounds as comorbidities to other conditions, patient adherence to therapy, and the economic burden of chronic wounds. The manuscript management system is completely online and includes a very quick and fair peer review system, which is all easy to use. Visit http://www.dovepress.com/testimonials.php to read real quotes from published authors.

Submit your manuscript here: https://www.dovepress.com/chronic-wound-care-management-and-research-journal 